\title{
PERFILES HERÁLDICOS Y NOBILIARIOS EN IBEROAMÉRICA
}

\section{HERALD AND NOBILITY PROFILES IN LATIN AMERICA}

\section{AUTOR}

\section{José L. Rodríguez Lizcano}

Escritor de varios artículos en revistas científicas y divulgativas (España)

rodríguezleizcano@hotmail.com

\section{RESUMEN}

La historia de España e I beroamericana está llena de hombres y mujeres que a lo largo del tiempo configuraron con su hacer de todos los días, lo que hoy reconocemos como nuestro acervo común.

\section{PALABRAS CLAVE}

Iberoamérica - Nobiliaria - Perfiles Heráldicos

\section{ABSTRACT}

The history of Spain and I bero is full of men and women who shaped over time with make every day, what we now recognize as our common inheritance.

\section{KEY WORDS}

Latin America - Nobility - Profiles Heraldic 


\section{REVISTA DE LA SEECI.}

Rodríguez Lizcano, José L. (1998): Perfiles heráldicos y nobiliarios en

Ineroamérica. $N^{\circ}$ 2. Noviembre. Año II. Páginas: 66-78

ISSN: 1576-3420 DOI: http://dx.doi.org/10.15198/seeci.1998.2.66-78

\section{ÍNDICE}

1. Nobiliaria.

1.1. Su papel en la historia.

2. La nobleza de indias.

2.1. Beneméritos.

3. Nobleza indígena.

3.1. Indios principales.

4. Heráldica.

4.1. La ciencia de los escudos.

4.2. ¿Qué es, por tanto, "Blasón"?

5. Heráldica.

5.1. I beroamericana.

6. Escudos de armas.

7. Genealogía y nobiliaria.

7.1. Moctezuma: emperador de los aztecas y de Méjico.

8. Bibliografía

"... la honra de los primeros tenedores de una merced, no está en los títulos que ostentan, sino en haberlos merecido"

S.A.R. Don Carlos María de Borbón Dos Sicilias

Duque de Calabria y Conde de Caserta

\section{Nobiliaria.}




\subsection{Su papel en la Historia}

Pasa esta modesta exposición una pequeña y sencilla muestra de las personas y los hechos que trajeron como consecuencia el merecimiento para adquirir la Nobleza, rememorando los Blasones de un grupo humano cuyas acciones contribuyeron de manera decisiva al devenir histórico de España e Iberoamérica, mostrando a la Sociedad algunos ejemplos vivos de un grupo de personas, cada cual en su momento, que por su esfuerzo y a veces con su sacrificio personal, influyeron de una manera positiva en el bien común.

De una parte importante de todo ello se encarga la Nobiliaria, que estudia los orígenes y evolución de la Nobleza, y su papel de transcendental importancia en la Historia, en las ordenes guerrero, político, económico, social, religioso, moral, literario y artístico, con sus grados, preeminencias y demás particularidades; y que indaga y establece los merecimientos que pueden servir de medios para adquirir, transmitir y suspender la Nobleza, bien sea por sangre o por privilegio.

Analiza sus actos positivos y la diferencia entre unos y otros para calificar los individuos pertenecientes al estado noble. Así, cada primer tenedor de una merced se nos hace presente en su momento histórico, ofreciendo a los ojos del lector un ejemplo gráfico en forma de Escudo de Armas o Blasón.

Tanto la parte de conceptos, como la gráfica tienen una doble utilidad práctica. De una parte, servirá a quienes deseen adquirir los primeros conocimientos sobre las "Armerías", en un plano puramente histórico, por el hecho de su creación, desarrollo y uso durante tantos siglos. Por otro lado, existe otra dimensión no menos importante, que es la aplicación actual de esa tradición, porque cada vez son más numerosas las personas que sienten la necesidad de buscar sus propias raíces y afirmar así su identidad. 
Todos nos podemos ver reflejados en este bien hacer, y ello atañe de una manera especial a los descendientes de estos titulados, que deben sentir el acicate de no ser menos que los primeros tenedores de la merced, en cuya representación hoy ellos la ostentan, cobijando no sólo al individuo sino también genéricamente, a la Casa, sus parientes, deudos y descendientes.

\section{La nobleza de indias.}

\subsection{Beneméritos.}

La historia de España e Iberoamérica está llena de hombres y mujeres que a lo largo del tiempo configuraron con su hacer de todos los días, lo que hoy reconocemos como nuestro acerco común. No obstante existe una gran confusión en cuanto al uso de la expresión "nobleza de indias", creyendo especialmente los profanos, que los "nobles de Indias" eran los nobles, de cualquier clase u origen que vivieran en las Indias.

La Nobleza de Indias fue la adquirida por los descubridores, conquistadores y primeros pobladores o colonizadores, llamados "Beneméritos de Indias". Llegaban a las Indias como pertenecientes al Estado Llano y por los méritos contraídos en el Nuevo Mundo eran elevados por el Rey a un especial "Estado de Distinción", con goces de derechos y preeminencias en los territorios de Indias, similares a los que gozaban los Hidalgos a Fuero de España.

El primer ejemplo que tenemos es la Nobleza otorgada por Real Cédula de 15 de enero de 1529 del Rey Carlos I a los pobladores de la Isla Española.

Se trataba de una situación sin precedentes en la Historia de España, en la que un grupo de hombres excepcionales partía en pos de la gloria, pues no era sólo el afán de riquezas el que los impulsaba, sin dudar un sólo instante en abandonarlo todo y lanzarse a una nueva aventura de exploración o conquistadora. 
Fieles vasallos aquellos que habiendo alcanzado la gloria y el poder por su propio esfuerzo, buscaban siempre en la palabra real la sanción de sus hechos y el fundamento de su autoridad. Suyo era el Nuevo Mundo y con su esfuerzo lo fueron conquistando para ofrecérselo al Rey.

En honor a su memoria y a la justicia, recordar que la exploración de las Américas por los españoles, fue la más grande, la más larga y la más maravillosa serie de valientes proezas que registra la historia. La obra misionera en América, al margen de abusos cometidos y de las calumnias de la Leyenda negra en contra de España y de la cultura hispánica, fue la luz que iluminó la colonización del Nuevo Mundo.

Al hablar de la historia y tradición española de Nuevo-México y de Nuestra Señora del Rosario "La Conquistadora", la imagen mariana más antigua de los actuales Estados Unidos de Norteamérica, bajo cuyo manto se custodia y respeta la Historia de los que allí llegaron por la "Fe de los españoles", trae a mi memoria este sencillo cuarteto:

Bastan los ojos del corazón para conocer,

bastan esos mismos ojos para amar,

un lugar que nunca he podido ver,

un lugar que no he llegado a pisar.

\section{Nobleza indígena.}

\subsection{Indios Principales.}


Pero no solamente existieron en las Indias la Nobleza de Indias y la Nobleza a Fuero de España si no que coexistió con la no menos importante de los "Indios Nobles", y desde el mismo momento del Descubrimiento la Corona les reconoció su posición social. Los "Reyes Nativos", "Príncipes" o "Emperadores" y los más modestos "Curacas", "Caciques" o "Capitanes Indios" y sus descendientes, gozando de una Nobleza (posteriormente recogido en las Leyes de Indias, comparable en todo a la de los Nobles Españoles, "Nobleza de Inmemorial" o "de Solar conocido", que no debe su nobleza al Rey sino que su antigüedad se pierde en la noche de los tiempos.

Todos estos indios merecedores de nobleza fueron llamados "Indios Principales", pero no bastando las costumbres, ni su admisión de palabra en un país tan legalista como el nuestro, se plasmaron tales costumbres en Leyes. Así tenemos que por una Real Cédula de 1545, el Emperador Carlos I de España y V de Alemania, reconocía a los caciques una altísima nobleza, por encima de la de los Grandes de España, llamándoles "hermano" y "hermana", y dándoles el tratamiento de Altexas, concediéndoles el Toison de Oro a perpetuidad, el derecho a permanecer cubiertos en su presencia, a presidir todos los tribunales, concejos y cabildos, y a mantener una pequeña corte y consejeros.

Las "Leyes de Indias" también recogieron el aspecto de la Nobleza de los Indios Principales, confirmado por Real Cédula de 12 de marzo de 1697 en donde se establece que: "... a los señores Caciques deben guardárseles en todos los aspectos y casos, las mismas exenciones y preeminencias que a los Hidalgos de Castilla". Siendo por lo tanto su nobleza superior a la reconocida para los descubridores y pobladores y en nada diferente a la Nobleza a Fuero de España.

El Cacique transmitía su cargo al estilo de la nobleza titulada, al hijo o hija, prefiriendo al de mayor edad sobre el más joven y al varón sobre la hembra, pudiendo heredar y transmitir el cargo y el rango. Sistema idéntico al entonces vigente para la transmisión de los "Títulos a Fuero de España", fácilmente 
comprendido y aceptado por los españoles en relación a sus nuevos súbditos. El resto de los hermanos y hermanas, e hijos del cacique, recibían también nobleza por agnición estricta. Fueron los llamados "Indios Principales".

En cuanto a los "Alcaldes Indios", a partir de 1545 no sólo se les reconocía su hidalguía, sino que se les autorizó a ejercer, a tales Alcaldes Indios la jurisdicción Civil o Criminal, en sus grados inferiores, no sólo sobre los indios de su demarcación, sino sobre cualquier persona que, dentro del territorio del tal alcalde, hubiera robado o matado, fuese esta persona blanca, india o negra.

\section{Heráldica.}

\subsection{La Ciencia de los Escudos.}

La ciencia heráldica es para la Real Academia Española: "El arte de explicar y describir los escudos de armas de cada linaje, ciudad o persona, confeccionando científica, perfecta y ordenadamente los blasones", de otra menos "Académica", podemos describirla como: "El arte que enseña a descifrar, componer, explicar y describir con acierto los escudos de armas o nobiliarios conforme a las leyes y reglas, usos y costumbres de cada nación".

\section{2 ¿Qué es por tanto "Blasón"?}

Pues sencillamente todo signo, figura, insignia o atributos determinados, o bien una combinación de ellos, que nos sirve para diferenciar a unos de otros los Estados, Provincias, Ciudades, Corporaciones, etc., de un modo permanente, y que con carácter hereditario a las familias e individuos, y que el J efe de una Nación o Estado concede en recompensa de "relevantes servicios". 
Fue utilizado en su origen casi con el único fin de distinguir a las personas y sus linajes (apellidos) y a través de él, como función identificativa y medio de acceso al conocimiento de su pasado genealógico.

De aquí que la Heráldica sea conocida también como la Ciencia, Teoría o Filosofía del "Blasón" o "Ciencia Heroica", ocupando un lugar preferente los llamados Escudos de Armas, de cuyo examen, descripción y estudio es objeto la Ciencia Heráldica, un sistema vivo que se transforma y evoluciona a la vez de su uso, muy flexible, capaz de adaptarse a las diferentes características de las manifestaciones plásticas fundamentalmente al valor estético.

Con el paso inevitable del tiempo, los diversos fines que abarca, la constante evolución de sus signos y otros factores, hicieron que su uso se multiplicase, ampliando sus campos a otras disciplinas o fuentes auxiliares, y en otros muchos casos aplicándose a reflejar cosas de muy distinta naturaleza.

Hoy cuando el culto a la imagen y la comunicación, discurren por vías más modernas que la secular del Blasón, no debemos confundirlo con otros métodos de representación figurada, basados en técnicas mas aptas para la publicidad que nos representan un determinado producto, marca de fábrica o industria, tales como son los "anagramas" y "logotipos". Estos no obedecen a reglas fijas, y son en efecto dibujados y coloreados al gusto personal, y naturalmente no son necesariamente hereditarios.

\section{Heráldica.}

\subsection{Iberoamericana.}


Aunque es muy amplio el panorama de la Heráldica, si no corriesen en nuestra época otros escudos que los propios de los condes y marqueses, las presentes páginas no habrían llegado a escribirse, pues lo que las mismas podrían contener derivaría a un hueco tan enorme que ningún trabajo del género lograría llenar.

Una amplia y detallada relación (con algunos comentarios) será ofrecida en próximos Boletines por la S.E.E.C.I., citando en este número (por razones de espacio) un solo blasón de armas, correspondiente a un Linaje o Apellido (el Emperador Moctezuma), que demostrará los extremos que justifican ante todo su empleo actual en las ciudades fundadas en América por los conquistadores españoles, que conservan las armas heráldicas o blasones concedidas por los sucesores de los Reyes Católicos, y que desde el paralelo 48 que circunda la cabeza de los Estados Unidos, hasta más abajo de la misma Latitud Sur, centenares de poblaciones americanas llevan nombre de ciudades y pueblos de España.

"Privilegios de Armas" compilados de documentos inéditos para la Historia de Hispano-América, como homenaje a todos los hombres y mujeres que aun habiendo merecido una merced, por distintos avatares, no se vieron agraciados con ella, y cuyo mayor ambición se cifraba en alzar una cruz y dejar unas piedras que perpetuasen sus trabajos y su memoria al otro lado del océano.

Por último, una pléyade inmensa de hombres anónimos, personas desconocidas, de toda índole, militares, científicos, descubridores, colonizadores, banqueros, administradores,... y otras mil profesiones que han merecido que su memoria histórica no pereciese.

A todos deseamos rendir nuestro homenaje de admiración y gratitud, y en su nombre señalamos algunos de ellos, cuya memoria aventa el incesante devenir del tiempo. 
Para aquellos quienes cándidamente toman los "escudos", "linajes" y "títulos nobiliarios" como un solo concepto, perdidos en el tiempo o arrinconadas en un desván, tal vez modificarán su opinión leyendo las páginas que siguen.

A los "maliciosos", nadie les disuadirá; para conseguirlo habría que hacerlos a todos "marqueses".

A los que "no quitan ojo" a sus habituales tareas, ven cada día los escudos "sin verlos", como un sabio entregado a sus meditaciones vagando por el campo más frondoso insensible al emotivo encanto del paisaje. A éstos quizás también les produjese sorpresa la apreciación de un arte cuyo vigor e importancia desconocían.

\section{Escudos de armas.}

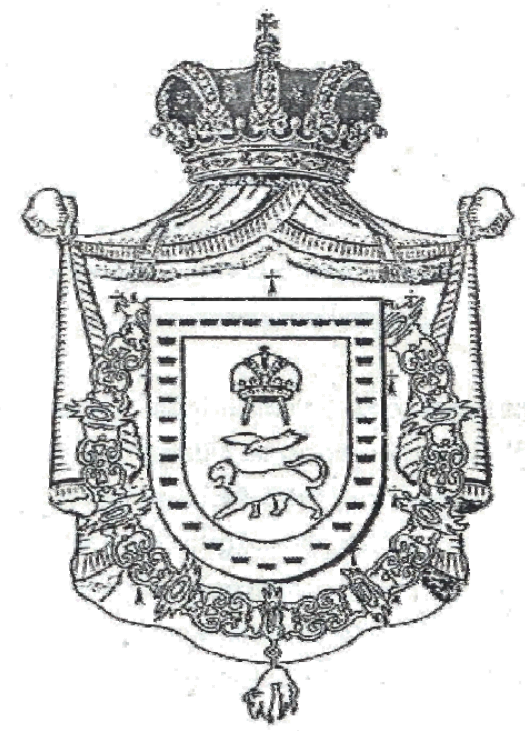

"En campo de azur, un tigre de plata, mirando con ademán fiero a un gavilán de oro, superado de Corona Imperial del mismo metal, que se cierne sobre él. Bordura de sinople, cargada de treinta coronas de oro". 


\section{Genealogía y Nobiliaria.}

Instituido para honrar la memoria del Emperador de los Aztecas Moctezuma I y creado como Condado en el año 1627 en la persona de Don Pedro Tesifón, bisnieto de Moctezuma II, y como tal portador de la más alta nobleza y posteriormente concedido por la Reina Doña Isabel II, por Real Decreto de 11 de Octubre de 1865, a Don Antonio María Marcilla de Teruel y Navarro Moctezuma, XIII Conde de Moctezuma, con Grandeza de España desde 1766. IX Marqués de Tenebrón. Caballero de la Gran Cruz de Carlos III y Maestrante de Zaragoza.

\subsection{Moctezuma: "Emperador de los Aztecas y de México"}

Fue Moctezuma II, Emperador de Méjico, nació en 1466 y murió en 1520. Fue esencialmente un Emperador guerrero. Su padre fue Moctezuma I, Emperador de los Aztecas, pero no sucedió él en el trono a su padre sino que el trono lo heredó un hermano de difunto rey y tío de Moctezuma II, el Rey Ahuitzotl. Muerto éste el nuevo Rey fue aclamado unánimamente para ocupar el trono por sus dotes guerreas y su carácter sacerdotal en el templo de Huitzilopochtli.

Se principal gloria está en las campañas guerreras con las que pretendía agrandar su imperio, por lo que toda su vida fue una continuada campaña. Como general casi siempre le acompañó el éxito, aunque no desconoció la derrota, a manos de los Tlascaltecas a los que una y otra vez durante toda su vida, arremetió con variada suerte.

Fue muy aficionado a la ostentación y a recibir los homenajes de sus súbditos, alejando de su corte a los que no eran nobles y destituyendo de todas sus funciones y dignidades a los plebeyos, para su mayor esplendor. 
Gran guerrero como era Moctezuma II no acertó a liberar a sus súbditos de las fuerzas españolas y los Conquistadores se apoderaron de la Ciudad de Méjico en donde entraron el 8 de noviembre de 1519, y al arengar Moctezuma II a sus súbditos que eran sitiados por los españoles, fue herido a pedradas por los indígenas aztecas, muriendo al poco tiempo, afirmando prestigiosos historiadores que murió de hambre por haberse negado a tomar alimentos. Su muerte acaeció el 30 de junio de 1520.

Había casado Moctezuma II con su sobrina Miacuachuchil, y de esta real pareja nació un hijo, el Príncipe Holca Huepautzin. Admitió el bautismo y tomó por nombre el de Pedro Moctezuma. Nieto de él era Pedro Tesifón, al que el Rey de España Felipe IV le concedió el I Condado de Moctezuma de Tultengo en 1627.

La línea Genealógica ha venido sucediendo el título hasta que el XIII Conde de Moctezuma fue creado I Duque del mismo nombre.

En 1902 el II Duque Don Luis Moctezuma Marcilla de Teruel, recibió la autorización de alterar el orden de sus apellidos y usar primero el de Moctezuma en recuerdo a su imperial antepasado.

En 1992 obtuvo la sucesión Don J uan José Marcilla de Teruel-Moctezuma y Jiménez, $\checkmark$ Duque y actual poseedor de la merced. Vizcone de llucan.

\section{Bibliografía}

APELLIDOS Y ESCUDOS QUE PASARON A INDIAS: J osé María de Mena

BIBLIOGRAFÍA HERÁLDICO- GENEALÓGICO-NOBILLARIA DE LA BILIOTECA NACIONAL (Manuscritos). Luis García Cubero 


\section{REVISTA DE LA SEECI.}

Rodríguez Lizcano, José L. (1998): Perfiles heráldicos y nobiliarios en

Ineroamérica. $N^{\circ}$ 2. Noviembre. Año II. Páginas: 66-78

ISSN: 1576-3420 DOI: http://dx.doi.org/10.15198/seeci.1998.2.66-78

CATÁLOGO DE LAS CONSULTAS DEL CONSEJ O DE INDIAS. Antonia Heredia Herreras CATÁLOGO DE PUBLICACIONES DE LA S.E.E.C.I. Información y comunicación bibliográfica especializada.

DICCIONARIO DE TíTULOS NOBILIARIOS. Julio de Atienza

DICCIONARIO HISPANOAMERICANO DE HERÁLDICA, ONOMÁSTICA Y GENEALOGÍA. Endika de Mogrobejo Ladrero.

DOCUMENTACIÓN PARTICULAR DEL AUTOR.

ENCICLOPEDIA HERÁLDICA Y GENEALÓGICA HISPANOAMERICANA. "Alberto $y$ Arturo García Carraffa."

FONDOS DOCUMENTALES DEL ARCHIVO GENERAL DE MARINA. "Posesiones en ultramar".

MARÍN CALAHORRO, Francisco. "Fundamentos del protocolo en la comunicación institucional".

CADENAS Y VICENT, A/V de. "Hereldario español, europeo y americano. CRESPO-FRANCÉS Y VALERO, J osé A. "La expedición de Juan Oñate".

VALERO BERNABÉ, Valero de; MÁRQUEZ DE LA PLATA, Vicenta. "Nobiliaria española. Libro de oro de los duques". 